\title{
Individual serological follow-up of patients with suspected or confirmed abdominal angiostrongyliasis
}

\author{
Penélope E Palominos, Rose Gasnier, Rubens Rodriguez ${ }^{1}$, Aventino A Agostini ${ }^{1}$, \\ Carlos Graeff-Teixeira/ ${ }^{+}$
}

\begin{abstract}
Laboratório de Parasitologia Molecular, Instituto de Pesquisas Biomédicas, Pontifícia Universidade Católica do Rio Grande do Sul (PUCRS) and Laboratório de Biologia Parasitária, Faculdade de Biociências da PUCRS, Avenida Ipiranga 6690, 2ªndar, Sala 20, 90690 900 Porto Alegre, Brasil 'Instituto de Patologia de Passo Fundo, Universidade de Passo Fundo, Passo Fundo, RS, Brasil
\end{abstract}

Abdominal angiostrongyliasis (AA) is a zoonotic nematode infection caused by Angiostrongylus costaricensis, with widespread occurrence in the Americas. Although the human infection may be highly prevalent, morbidity is low in Southern Brazil. Confirmed diagnosis is based on finding parasitic structures in pathological examination of biopsies or surgical resections. Serology stands as an important diagnostic tool in the less severe courses of the infection. Our objective is to describe the follow up of humoral reactivity every 2-4 weeks up to one year, in six individuals with confirmed $(C)$ and ten suspected $(S)$ AA. Antibody $(\operatorname{IgG})$ detection was performed by ELISA and resulted in gradually declining curves of reactivity in nine subjects $(56 \%)(4 C+5 S)$, that were consistently negative in only three of them $(2 C+1 S)$ after 221, 121 and 298 days. Three individuals $(2 C+1 S)$ presented with low persistent reacitivity, other two $(1 C+1 S)$ were serologically negative from the beginning, but also presenting a declining tendency. The study shows indications that abdominal angiostrongyliasis is usually not a persistent infection: although serological negativation may take many months, IgG reactivity is usually declining along time and serum samples pairing may add valuable information to the diagnostic workout.

Key words: abdominal angiostrongyliasis - Angiostrongylus costaricensis - eosinophilic gastroenteritis - zoonosis

Abdominal angiostrongyliasis (AA) is a nematode infection caused by Angiostrongylus costaricensis. Wild rodents are the definitive hosts and larval stages develop in terrestrial mollusks (Morera 1971). The parasitosis occurs mainly in the Americas, from Southern USA to Northern Argentina and Southern Brazil (Ubelaker \& Hall 1979, Agostini et al. 1984, Demo \& Pessat 1986). Imported infections have been diagnosed in USA, Europe and probably in Africa (Baird et al. 1987, Silvera et al. 1989, Vázquez et al. 1993). Accidental human infection may present as acute abdominal disease that usually affects the ileo-cecum transition with an inflammatory reaction mainly produced by secreted antigens and the presence of eggs in small capillaries. The disease may complicate with intestinal obstruction due to extensive eosinophilic infiltration and intestinal perforation, peritonitis and sepsis, secondary to arterial thrombosis and necrosis (Céspedes et al. 1967). Detection of parasite structures in examination of biopsies or surgical specimens allows the definitive diagnosis. In the absence of intra-arterial worms or eggs, histological findings such as severe eosinophilic infiltration, granulomatous reaction and eosinophilic vasculitis lead to a suspected diagnosis (Graeff-Teixeira et al.1991a). Serology is essential for the diagnostic workout in uncomplicated clinical cases, since

Finantial support: PUCRS (FABIO, IPB and Hospital São Lucas), CNPq (477782/2004-3, 307872/2004-1), FAPERGS

+ Corresponding author: graeteix@pucrs.br

Received 19 October 2007

Accepted 11 February 2008 fecal elimination of parasitic structures have never been reported. Previous evaluations of $\operatorname{IgE}, \operatorname{IgM}, \operatorname{Ig} \mathrm{A}$ or isotypes of IgG anti-crude adult worm antigens did not result a better diagnostic tool than an IgG-ELISA currently in use (Geiger et al. 2001). Our objective is to report the follow up of $\operatorname{IgG}$ anti- $A$. costaricensis production in patients from the endemic area in Southern Brazil.

\section{PATIENTS, MATERIAL AND METHODS}

Patients - A number of pathology laboratories and clinical services in the Brazilian southernmost state, Rio Grande do Sul, are included in a vigilance network looking for suspected or confirmed new cases of AA, according to previously described histopathological criteria (Graeff-Teixeira et al. 1991a). Briefly, the detection of parasite structures (intra-arterial worms or eggs) is the mainstay for a confirmed diagnosis, while the intense eosinophillic inflammatory response in the intestinal wall, the eosinophilic vasculitis (especially in arteries) and granulomatous reaction (including granulomatous arteritis) support the suspicion of $A$. costaricensis infection (Agostini et al. 1984). From 1999 to 2003, six patients with confirmed abdominal angiostrongyliasis (group C) and ten with suspected diagnosis (group S) had a serological follow-up for $298 \pm 156$ (media \pm standard deviation) and $409 \pm 212$ days, respectively (Table). The collection of blood samples were scheduled as follows: one initial sample immediately after the diagnosis and samples every two weeks for three months and every month up to one year. Time zero was the date of the surgical procedure. Large variation in the intervals for sample collection occurred because patients and health services did the sampling at their convenience, not necessarily as sched- 
TABLE

Length of serological follow-up in 16 patients with suspected or confirmed abdominal angiostrongyliasis in Southern Brazil

\begin{tabular}{|c|c|c|c|c|}
\hline Initials $^{a}$ & Age (years) & Sex & $\begin{array}{l}\text { Days before consistent } \\
\text { negative serology }\end{array}$ & $\begin{array}{l}\text { Total days } \\
\text { of follow-up }\end{array}$ \\
\hline \multicolumn{5}{|l|}{ Suspected diagnosis } \\
\hline MTD - S & 49 & $\mathrm{f}$ & - & 188 \\
\hline IW - S & 26 & $\mathrm{f}$ & - & 236 \\
\hline $\mathrm{CP}-\mathrm{S}$ & 79 & $\mathrm{f}$ & 221 & 287 \\
\hline $\mathrm{ABN}-\mathrm{S}$ & 13 & $\mathrm{f}$ & $1^{b}$ & 300 \\
\hline $\mathrm{OB}-\mathrm{S}$ & 27 & $\mathrm{~m}$ & 121 & 378 \\
\hline $\mathrm{EF}-\mathrm{S}$ & 44 & $\mathrm{f}$ & - & 392 \\
\hline LG - S & 32 & $\mathrm{f}$ & - & 458 \\
\hline MF - S & 35 & $\mathrm{f}$ & - & 459 \\
\hline DS - S & 55 & $\mathrm{~m}$ & - & 538 \\
\hline LW - S & 30 & $\mathrm{~m}$ & - & 842 \\
\hline mean \pm standard deviation & $39 \pm 19$ & & & $409 \pm 212$ \\
\hline \multicolumn{5}{|l|}{ Confirmed diagnosis } \\
\hline $\mathrm{EC}-\mathrm{C}$ & 18 & $\mathrm{f}$ & - & 69 \\
\hline MDP - C & 48 & $\mathrm{f}$ & - & 181 \\
\hline $\mathrm{FM}-\mathrm{C}$ & 10 & $\mathrm{f}$ & - & 300 \\
\hline $\mathrm{EB}-\mathrm{C}$ & 49 & $\mathrm{~m}$ & 298 & 330 \\
\hline NGP - C & 32 & $\mathrm{f}$ & 1 & 399 \\
\hline IB - C & 48 & $\mathrm{~m}$ & - & 506 \\
\hline mean \pm standard deviation & $35 \pm 18$ & & & $298 \pm 156$ \\
\hline
\end{tabular}

$a$ : initials plus the indication of suspected (S) or confirmed (C) diagnosis; $b$ : patients with negative serology from the beginning.

uled by the research protocol. Serum was immediately separated, eventually stored locally at $-20^{\circ} \mathrm{C}$ and kept in ice for transportation, never longer than two days, before final storage at $-80^{\circ} \mathrm{C}$ at PUCRS laboratories.

The parasite and ELISA - A. costaricensis, Santa Rosa and Nova Itaberaba strains, are maintained in vivo at the laboratory through passages in Swiss mice or Oligoryzomis nigripes and Biomphalaria glabrata (Esteio strain). Details of antigen preparation and ELISA methodology are described elsewhere (Graeff-Teixeira et al. 1997, Geiger et al. 2001). In brief, the immunoenzymatic assay was performed using crude female worm antigens with sensitivity and specificity of $76 \%$ and $91 \%$, respectively. Results of the ELISA are expressed as a ratio: average optical density from duplicates/cut-off value as described by Geiger et al. (2001).

Bioethics - Informed consent was obtained from all adult participants and from parents or legal guardians of minors, with the name of the appropriate institutional review board having approved the project. The investigation protocol was approved by the ethical committee (CEPPUCRS, 15 december 1999) and performed according to Brazilian regulation (Resolução MS-CNS 196/96).

\section{RESULTS}

The individual $\mathrm{IgG}$ reactivity is shown graphically in Figs 1, 2, 3 and 4. Nine of them (4 from group $\mathrm{C}$ and 5 from group $\mathrm{S}$ ) presented gradually declining curves, although only three ( 2 from group $\mathrm{C}$ and 1 from group S) had a consistently negative ELISA after 221, 121 and 298 days $(214 \pm 89)$ (Table). Two patients (NGP-C and ABN-S) were serologically negative from the beginning, but both showed a tendency to reduce the reactivity, especially ABN-S (Fig. 4). Other two patients (EC-C and EF-S) were persistently positive at very low antibody titers (Fig. 4). Some individuals (MDP-C in Fig. 1; MF-S and IW-S in Fig. 3) presented a low initial reactivity level before a sharp increase at $53 \pm 10$ days. IB-C (Fig. 1) showed a striking reduction at 157 days and another peak of reactivity at 220 days with gradual decline up to 506 days. In spite of clinical follow-up data not being presented because they were not available all the time from most of the patients, convalesce was usually symptomfree and all of them survived.

\section{DISCUSSION}

Sero-epidemiological studies have demonstrated accidental human infection with $A$. costaricensis to be very frequent, while morbidity is usually very low (GraeffTeixeira et al. 2005). Severe cases requiring surgical treatment for perforation and/or intestinal obstruction are rare in Southern Brazil as can be illustrated by the low number of cases with definitive diagnosis in the present study.

As indicated by a preliminary evaluation, antibody response gradually decreases along time, indicating that the worms do not survive long time in humans (Geiger et al. 2005). The inappropriateness of the classic wisdom that the infection courses with high morbidity in a less adapted host, is illustrated by the situation in human AA, where cycle is not completed and adult worms do not survive a long time, but infection only rarely manifests its more extreme "virulence" or "pathogenicity". This situation fits in the proposition of alternative models to describe host-parasite coevolutionary status, like the 

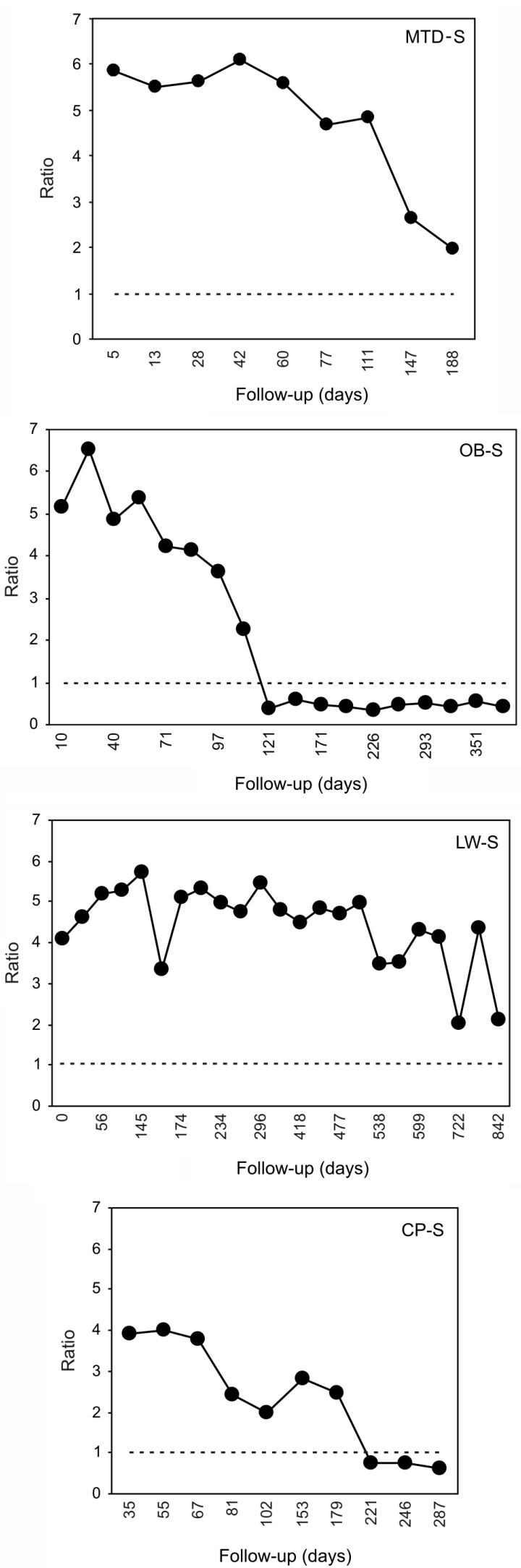

Fig. 1: IgG reactivity in an anti-Angiostrongylus costaricensis antibody detection ELISA. Four patients (MTD-S, OB-S, LW-S and $\mathrm{CP}-\mathrm{S}$ ) with suspected diagnosis (S). OB-S shows a very sharp decline and persistent negative serology from 121 days onwards.
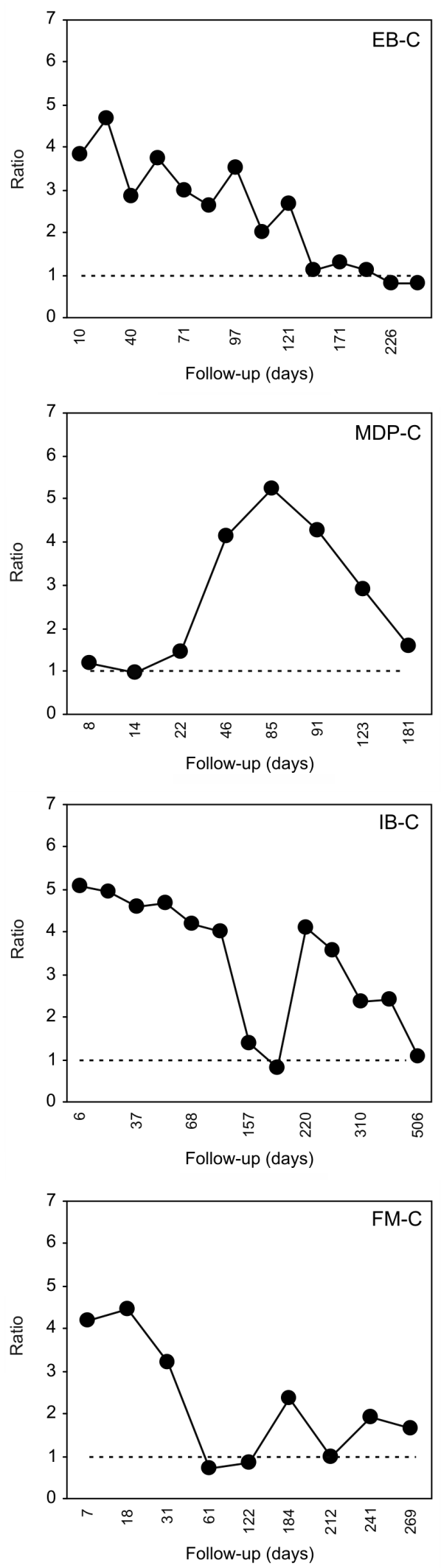

Fig. 2: IgG reactivity in an anti-Angiostrongylus costaricensis antibody detection ELISA. Confirmed abdominal angiostrongyliasis diagnosis (C). Patient MDP-C presents a curve with a delayed peak as also seen with IW-S and MF-S in Fig 3. A boost in reactivity is seen after 220 days in the follow-up of IB-C. 

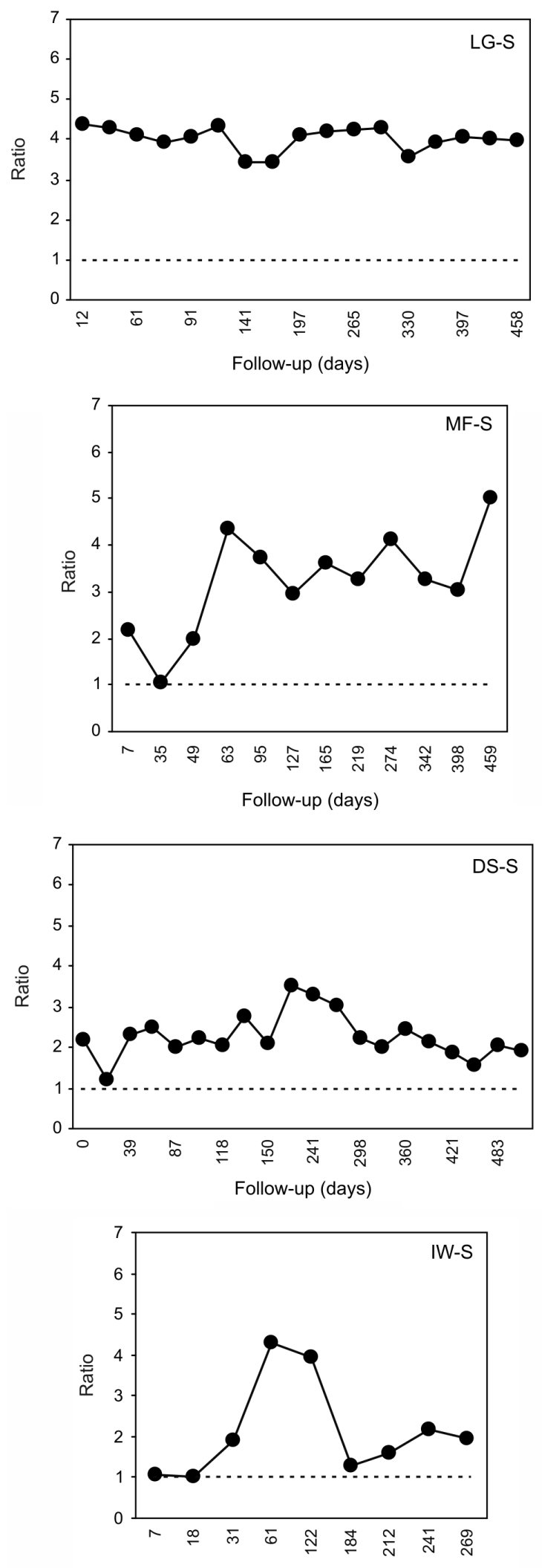

Follow-up (days)

Fig. 3: IgG reactivity in an anti-Angiostrongylus costaricensis antibody detection ELISA. Four patients with suspected diagnosis (S) and persistent positive reactivity. Patients MF-S and IW-S show a delayed peak at 63 and 59 days post acute phase.
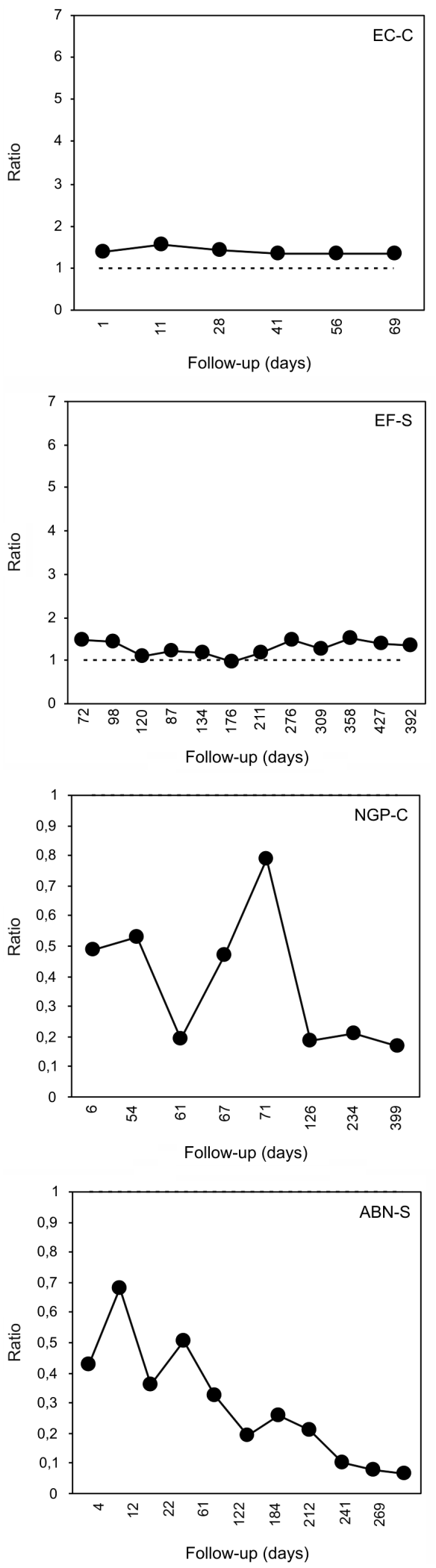

Fig. 4: IgG reactivity in an anti-Angiostrongylus costaricensis antibody detection ELISA. Very low reactivity: patients EC-C and EF-S persistently above the cut-off; NGP-C and ABN-S below the cut-off (notice that ratio 1 is the top value in " $y$ " axis). Although a formal negative result in ELISA, especially patient ABN-S shows a declining tendency in $\operatorname{IgG}$ reactivity. 
"titer-time curve" of parasite transmission forms made available for the infection of new hosts, thereby favoring parasite species survival in nature (Garnik 1992).

Because of the difficulties for detection of L1 in stools, serology is a key diagnostic methodology to reveal the presence sub-clinical or asymptomatic courses of AA. Serology may also help the follow-up of patients leading to early detection of complications requiring surgical treatment. One patient (MDP-C, Fig. 1) had a dramatic increase in reactivity coincident with a recurrence of severe intestinal inflammatory lesions leading to a second surgical intervention. IB-C (Fig. 1) also showed a second peak which was not related to new lesions, suggesting reinfection. On the other hand, a decrease in antibody titer is apparently a good prognostic sign.

Several patterns of reactivity may be delineated from these data: (1) a predominant gradually decreasing reactivity (EB-C, Fig. 1 and OB-S, Fig. 2); persistently positive in (2) high (LG-S and MF-S, Fig. 3) and (3) low titers (DS-S, Fig. 3; EC-C and EF-S, Fig. 4); and (4) delayed peak reactivity (MDP-C, Fig. 1; MF-S and IW-S, Fig. 3).

The similarity of reactivity curves in several patterns both from confirmed and suspected abdominal angiostrongyliasis add validation to clinical and histopathological criteria as previously established (Agostini et al. 1984, Graeff-Teixeira et al. 1991a).

The persistence of antibodies for many months, either in high or low titers, was not previously detected, since all patients in the evalution by Geiger et al. (2001) were serologically negative from three months onwards. Although rare, the most intriguing situations are the persistent high titers, like the curve from LG-S (Fig. 3) or LW-S (Fig. 2), suggesting persistence of infection for a longer than expected time.

Part of the problems of sensitivity of immunological methods may be explained by the low responders. Variability and diversity of antibody response to a parasite infection should be taken in consideration when diagnostic methods are under analysis. More extensive observations with clinical, parasitological and serological follow-up are required for better evaluation of prognostic value of serological and other molecular methods in abdominal angiostrongyliasis.

\section{ACKNOWLEDGEMENTS}

To Ingrid Porto and Juliano Romanzini for technical help. Serum samples collections were made possible through cooperation from the following Institutions and individuals: Ana CA Silva, Antonio C Laitano, Caroline P Andrade, Fabiane Rigotti, Fabiane W Cidade, Maria F Pellicioli, Márcia CF Silva, Pablo B Bubols, Paula B Terraciano, Rafael L Maurer, Renata Ben, Roberta K Barbosa (FABIO/IPB PUCRS); Aventino A Agostini and Rubens Rodriguez (Instituto de Patologia de Passo Fundo); Ana M Gaiger (Lab Pat Reunidos, P.Alegre); Alex Guerini (Hospital Nonoai); Altair Collares (Hospital de Sarandi); Altair Copatti and Glaé Lameira (Hospital Santo Antônio, Três de Maio); Anencir F Silva, Irmã Romana, Rosane Perios and Nídia Perios (Hospital Cândido Godoi); Auristela Barros (SM Saúde, Planalto), Carlos Reichel (FAMED, PUCRS), Carlos Muneroli and Tânia Otto (Hospital Comunitário de Carazinho); Clóvis Bringuenti (Laboratório Vital, Nonoai); Eglê de Almeida (Hospital Cristo Redentor, Marau);
Gilberto Mayer (Hospital São Vicente, Passo Fundo); Janice P Zanella (Laboratório Sta Maria, Planalto); João Mesquita (Hospital Cesar Santos, Passo Fundo); José HM Silva (Lab das Clínicas, Passo Fundo), Paulo Sommer and Ursula Bockwinkel (Hosp Porto Xavier); Paulo Valiatti (Lab Fontoura Xavier) and Laboratório Biolabor (Marau).

\section{REFERENCES}

Agostini AA, Marcolan AM, Lisot JMC, Lisot JUF 1984. Angiostrongilíase abdominal. Estudo anátomo-patológico de quatro casos observados no Rio Grande do Sul, Brasil. Mem Inst Oswaldo Cruz 79: 443-445.

Baird JK, Neafie RC, Lanoie L, Connor DH 1987. Abdominal angiostrongylosis in an african man: case study. Am J Trop Med Hyg 37: 353-356.

Cespedes R, Salas J, Mekbel S, Troper L, Mullner F, Morera P 1967. Granulomas entericos y linfaticos con intensa eosinofilia tisular producidos por un estrongilideo (Strongylata): I. Patologia. Acta Med Costarric 10: 235-255.

Demo OJ, Pessat OAN 1986. Angiostrongilosis abdominal. Primer caso humano encontrado em Argentina. Prensa Med Argentina 73: $732-738$.

Garnik E 1992. Parasite virulence and parasite-host coevolution: a reappraisal. J Parasitol 78: 381-386.

Geiger SM, Laitano AC, Sievers-Tostes C, Agostini AA, Schulz-Key H, Graeff-Teixeira C 2001. Detection of the acute phase of abdominal angiostrongyliasis with a parasite-specific IgG enzyme linked immunosorbent assay. Mem Inst Oswaldo Cruz 96: 515-518.

Graeff-Teixeira C, Camillo-Coura L, Lenzi HL 1991a. Histopathological criteria for diagnosis of abdominal angiostrongyliasis. Parasitol Res 77: 606-611.

Graeff-Teixeira C, Camillo-Coura L, Lenzi HL 1991b. Clinical and epidemiological studies on abdominal angiostrongyliasis in southern Brazil. Rev Inst Med Trop Sao Paulo 33: 375-380.

Graeff-Teixeira C, Ferreira-da-Cruz MF, Agostini AA, CamilloCoura L 1997. Standartization of na immunoenzymatic assay (ELISA) for seroepidemiology of abdominal angiostrongyliasis. Trop Med Internat Health 2: 254-260.

Graeff-Teixeira C, Goulart AH, Brum CO, Laitano AC, Sievers-Tostes C, Zanini GM, Bered PL, Morassutti A, Geiger S, Abrahms-Sandi E, Oliveira FTS, Maurer RL, Aguiar LF, Garrido CT, Silva ACA, Rodriguez R, Schultzk-Key H, Agostini AA 2005. Longitudinal clinical and serological survey of abdominal angiostrongyliasis in Guaporé, southern Brazil, from 1995 to 1999. Rev Soc Bras Med Trop 38: 310-315.

Morera P 1973. Life history and redescription of Angiostrongylus costaricensis Morera and Céspedes, 1971. Am J Trop Med Hyg 22: 613-621.

Silva ACA, Graeff-Teixeira C, Zaha A 2003. Diagnosis of abdominal angiostrongyliasis by PCR from sera of patients. Rev Inst Med Trop Sao Paulo 45: 295-297.

Silvera CT, Ghali VS, Roven S, Heiman J, Gelb A 1989. Angiostrongyliasis: a rare cause of gastrointestinal hemorrhage. $\mathrm{Am}$ J Gastroenterol 84: 329-332.

Ubelaker JE, Hall NM 1979. First Report of Angiostrongylus costaricensis Morera \& Céspedes, 1971 in the United States. J Parasitol 65: 307.

Vázquez J, Boils PL, Sola JJ, Carbonell F, Burgueño MJ, Giner V, Berenguer-Lapuerta J 1993. Angiostrongyliasis in a European patient: a rare cause of gangrenous ischemic enterocolitis. Gastroenterology 105: 1544-1549. 